\title{
QUANTIFICAÇÃO E CORRELAÇÕES DE PARÂMETROS MICROBIOLÓGICOS EM QUEIJOS MINAS FRESCAL NO SUDOESTE DA BAHIA
}

\author{
Vanessa Daniele Mottin ${ }^{1}$ \\ Larissa Lima Silva ${ }^{2}$ \\ Joselia Nascimento Rocha \\ Milton Rezende Teixeira Neto ${ }^{1}$
}

MOTTIN, V. D.; SILVA, L. L.; ROCHA, J. N.; TEIXEIRA NETO, M. R. Quantificação e correlações de parâmetros microbiológicos em queijos minas frescal no sudoeste da Bahia. Arq. Ciênc. Vet. Zool. UNIPAR, Umuarama, v. 19, n. 3, p. 137-142, jul./set. 2016.

RESUMO: O Queijo Minas Frescal é um dos derivados do leite mais consumidos no Brasil, considerado como um queijo semigordo e de muito alta umidade, característica que propicia a contaminação por micro-organismos. Nesse sentido, o objetivo desse estudo foi verificar quantitativamente a ocorrência de Staphylococcus coagulase positiva, coliformes totais e Escherichia coli nos queijos Minas Frescal do Sudoeste da Bahia, bem como, as suas correlações. Para isso, foram analisadas três marcas de queijos comercializadas na região, sendo coletadas amostras, em duplicata, de três diferentes lotes. Os resultados foram obtidos pela contagem de colônias características e expressos em UFC/g. Os dados foram apresentados de forma descritiva e as correlações entre os parâmetros foram avaliadas por meio da equação linear de Pearson. Todas as amostras analisadas estavam contaminadas com Staphylococcus coagulase positiva e coliformes totais acima do limite estabelecido pela legislação. Para o parâmetro Escherichia coli, somente 16,6\% estavam dentro do limite estabelecido pela legislação vigente. As correlações entre as contagens de Staphylococcus coagulase positiva com Escherichia coli e coliformes totais foram moderadas e negativas (-0,32 e -0,32, respectivamente), e entre Escherichia coli e coliformes totais foi positiva e elevada $(0,99)$. Os produtos analisados encontraram-se impróprios ao consumo, sendo que, apenas uma marca destacou-se por estar em conformidade com a legislação para um dos parâmetros. Assim, entende-se que as condições higiênico-sanitárias para a fabricação do produto podem não estar adequadas, representando um risco ao consumidor final.

PALAVRAS-CHAVE: Derivados lácteos. Indicadores de qualidade. Indicadores de segurança.

\section{QUANTIFICATION AND CORRELATION OF MICROBIOLOGICAL PARAMETERS ON MINAS FRESCAL CHEESES IN THE SOUTH-WESTERN BAHIA}

\begin{abstract}
Minas Frescal cheese is one of the most consumed milk derivatives in Brazil. It is considered a semi-fat cheese with very high humidity content. Such characteristic eases the contamination by micro-organisms. Therefore, the purpose of this study was to quantitatively assess the occurrence of positive coagulase Staphylococcus, total coliforms, and Escherichia coli on Minas Frescal cheese from south-western Bahia, as well as their correlations. In order to do so, three brands of cheese marketed in the region were analyzed, with samples being collected in duplicated from three different batches. The results were obtained by the count of characteristics colonies and expressed in UFC/g. Data were presented in a descriptive way and the correlations among the parameters were evaluated using the Pearson linear equation. All the samples analyzed presented positive coagulase Staphylococcus contamination and total coliforms above the limit established in legislation. For the Escherichia coli parameter, only $16.6 \%$ samples were within the limit stablished by the current legislation. Correlations between the positive coagulase Staphylococcus count, Escherichia coli and total coliforms were moderate and negative (-0.32 and -0.32, respectively), and between Escherichia coli and total coliforms was positive and high (0.99). Therefore, the products analyzed are considered unfit for consumption, with only one brand being considered compliant with the legislation in one of the parameters. Thus, it is understood that the hygienic-sanitary conditions for the manufacturing of such product may not be adequate, posing a risk to the final consumer.
\end{abstract}

KEYWORDS: Milk derivate. Quality indicators. Safety indicators.

\section{CUANTIFICACIÓN Y CORRELACIONES DE PARÁMETROS MICROBIOLÓGICOS EN QUESOS FRESCAL MINAS EN EL SUROESTE DE BAHÍA}

RESUMEN: El Queso Frescal Minas es uno de los derivados de la leche más consumidos en Brasil, considerado como un queso semigrasa y de mucha alta humedad, característica que proporciona la contaminación por microorganismos. En este sentido, el objetivo de este estudio fue verificar cuantitativamente la presencia de Staphylococcus coagulasa positivo, coliformes totales y Escherichia coli en quesos Frescal Minas del suroeste de Bahía, así como sus correlaciones. Para ello, se analizaron tres marcas de queso que se comercializan en la región, las muestras se recogieron por duplicado de tres lotes

DOI: https://doi.org/10.25110/arqvet.v19i3.2016.6084

${ }^{1}$ Faculdade de Tecnologia e Ciências. Rua Ubaldino Figueira, nº. 200, Bairro: Exposição. Vitória da Conquista - BA. CEP: 45.020-510. vmottin@yahoo. com.br

${ }^{2}$ Nutricionista 
diferentes. Los resultados se obtuvieron mediante el recuento de colonias características expresadas en UFC /g. Los datos se presentaron de forma descriptiva y correlaciones entre los parámetros fueron evaluados por la ecuación lineal de Pearson. Todas las muestras analizadas estaban contaminadas con Staphylococcus coagulasa positivos y coliformes totales por encima del límite establecido por la ley. Para el parámetro de Escherichia coli, sólo el 16,6 \% estaban dentro del límite establecido por la ley. Las correlaciones entre conteo de Staphylococcus coagulasa positiva con Escherichia coli y coliformes totales fueron moderados y negativos (-0.32 -0.32, respectivamente), y entre Escherichia coli y coliformes totales fue positiva y alta $(0,99)$. Los productos examinados se encontraron impropios para el consumo, siendo que, sólo una marca se destacó por estar en conformidad con la legislación para uno de los parámetros. Así, se entiende que las condiciones sanitarias para la fabricación del producto pueden no estar apropiadas, representado un riesgo para el consumidor.

PALABRAS CLAVE: Derivados lácteos. Indicadores de calidad. Indicadores de seguridad

\section{Introdução}

O Queijo Minas Frescal pode ser definido como um queijo fresco obtido por coagulação enzimática do leite com coalho e/ou outras enzimas coagulantes apropriadas, complementada ou não com ação de bactérias lácticas específicas. Este queijo é classificado como semi-gordo e de alta umidade (BRASIL, 1996).

Dentre os derivados lácteos de maior consumo, destaca-se queijo, e dentre as principais matérias primas para a fabricação do queijo, o leite. A partir disto é importante assegurar sua integridade, a fim de que o queijo tenha menor número e variedade de contaminantes dentro das normas estabelecidas pela RDC (PINTO et al., 2011).

O primeiro passo para uma adequada fabricação de queijo é a condição higiênico sanitária, que vai desde a ordenha até o a produção, armazenamento e transporte do subproduto (PICOLI et al., 2006).

No nordeste, grande parte da produção dos queijos é realizada em pequenas queijarias, representando grande preocupação. Geralmente nestes locais a segurança microbiológica do processo é inferior àquela utilizada em indústrias, e consequentemente, aumenta o risco do produto ter alguma não conformidade e do consumidor apresentar uma Doença Transmitida por Alimentos (DTA) (SANTANA et al., 2008).

A RDC 12 de janeiro de 2001 estabelece parâmetros microbiológicos para alimentos de consumo humano. Segundo ela, Staphylococcus coagulase positiva e coliformes termotolerantes são dois dos micro-organismos citados que devem ser pesquisados para assegurar a qualidade do queijo Minas Frescal (BRASIL, 2001). Além desta, a Portaria 146 de março de 1996 traz o Regulamento Técnico de Identidade e Qualidade de Queijos, na qual cita alguns parâmetro microbiológicos, e dentre eles, o grupo dos coliformes totais (BRASIL 1996).

Entre as espécies do gênero Staphyloccocus, a mais frequentemente encontrada em episódios de intoxicações alimentares é $S$. aureus, em função da produção de diferentes exotoxinas (BORGES et al., 2008), sendo estas muito patogênicas e responsáveis por surtos muito significativos (JAY, 2005; FORSYTHE, 2013). Além de estar altamente presente em manipuladores de alimentos (MOTTIN; ABREU, 2011) e de ser uma das bactérias que mais rapidamente se proliferam, sua resistência aos antimicrobianos caracteriza este micro-organismo como um dos mais importantes à Saúde Pública (ARRUDA, 2006). A intoxicação por Staphyloccocus tem gerado surtos e casos esporádicos de intoxicação atribuídos ao consumo de derivados lácteos, principalmente queijos.

No que tange aos coliformes, Silva, Junqueira e Silveira (2001) destacam que são enterobactérias gram-ne- gativas, em forma de bastonetes, aeróbios ou anaeróbios facultativos, não esporogênicos que possuem capacidade para fermentar a lactose com produção de gás a $35^{\circ} \mathrm{C}$. A quantidade de coliformes totais presentes em alimentos sugere as condições higiênicas do ambiente de processamento de alimentos (SOUSA, 2006).

A Escherichia coli é uma das bactérias mais pesquisadas em alimentos e principal representante do grupo dos coliformes termotolerantes, ou coliformes à $45^{\circ} \mathrm{C}$, ou anteriormente denominados de coliformes fecais (VIEIRA et al., 2008; JAY, 2005). Tem como característica principal ser encontrada no intestino humano ou animal, no entanto, pode também ser encontradas na natureza, onde permanece viável mais tempo que as bactérias citadas acima (SILVA; CAVALLI; OLIVEIRA, 2006). É caracterizada por ser Gram negativa, fermentadora de lactose com consequente produção de gás (JAY, 2005; TORTORA et al., 2012). Essa característica tem como consequência, além da alteração das características organolépticas do alimento, o estufamento da embalagem (PINTO et al., 2011).

Em função destas características, o objetivo desta pesquisa foi verificar quantitativamente a ocorrência de Staphylococcus coagulase positiva, coliformes totais e Escherichia coli nos queijos Minas Frescal do Sudoeste da Bahia.

\section{Material e Métodos}

As amostras foram analisadas em um laboratório de análises de alimentos e água localizado no município de Vitória da Conquista, Bahia, o qual realiza ensaios para o controle de qualidade para maioria das indústrias de alimentos da região.

Foram analisadas dezoito amostras de queijo Minas Frescal, sendo três lotes diferentes de três marcas comerciais e de fabricação industrial, inspecionadas pelo Serviço de Inspeção Federal. Duas amostras de cada lote das marcas estudadas foram adquiridas semanalmente e analisadas em duplicata para maior confiabilidade dos resultados. As marcas foram selecionadas a partir de um levantamento nos supermercados da cidade - do total de sete marcas comercializadas, três estavam presentes em todos os locais visitados.

Após a coleta, as amostras foram acondicionadas em caixas isotérmicas contendo gelo e transportadas imediatamente ao laboratório; foi realizada desinfecção nas embalagens utilizando álcool $70^{\circ} \mathrm{GL}$ e todo o procedimento de análise foi realizado assepticamente.

As análises foram realizadas de acordo com metodologia descrita pela Instrução Normativa $n^{0} 62$, de 26 de agosto de 2003 (BRASIL, 2003): 25 gramas de cada amostra foram diluídas em $225 \mathrm{~mL}$ de água peptonada tamponada e, 
a partir desta, diluições seriadas foram preparadas.

Para contagem do gênero Staphylococcus foi utilizada a técnica de semeadura em superfície com o auxílio de alça de Drigalsky, a partir da inoculação de $0,1 \mathrm{~mL}$ das diluições em placas contendo ágar Baird-Parker suplementado com solução de gema de ovo a $50 \%$ com telurito de potássio.

As placas foram incubadas a $37^{\circ} \mathrm{C}$ por 48 horas. Neste período ocorre redução anaeróbica e aeróbica do telurito de potássio pelos Staphylococcus coagulase positiva, havendo produção de colônias negras com formação de um halo de transparência e um de precipitação devido, respectivamente, às atividades proteolítica e lipolítica do micro-organismo.

As colônias características foram contadas e três destas selecionadas para a realização de provas de triagem, como coloração de Gram e catalase.

Posteriormente, as colônias com arranjo de estafilococos Gram positivos e catalase positivas foram inoculadas em tubos de ensaio contendo caldo Infusão Cérebro Coração (BHI) e incubadas a $37^{\circ} \mathrm{C}$ por 24 horas. A presença de Staphylococcus coagulase positiva foi confirmada por meio da prova da coagulase em tubos. A partir do percentual de posi- tividade destes, foram realizados cálculos sobre o número total de unidades formadoras de colônias (UFC) crescidas em ágar Baird-Parker e os resultados foram expressos em UFC/g do alimento.

As análises de coliformes totais e $E$. coli foram realizadas pelo método Petrifilm EC, seguindo instruções do fabricante (3M). Inoculou-se $1 \mathrm{~mL}$ das diluições nas placas e incubou-se a $37^{\circ} \mathrm{C}$ por 24 horas.

Os resultados foram obtidos pela contagem de colônias características e expressos em UFC/g. Os dados foram apresentados de forma descritiva e as correlações entre os parâmetros foram avaliadas por meio da equação linear de Pearson do PROC CORR (SAS, versão 9.0), sendo consideradas significativas com $\mathrm{P}<0,01$.

\section{Resultados e Discussão}

A presença Staphylococcus coagulase positiva foi acima do limite estabelecido pela legislação (BRASIL, 2001) em $100 \%$ das amostras, sendo que as médias encontradas foram muito superiores ao padrão de $5 \times 10^{2} \mathrm{UFC} / \mathrm{g}$ (Tabela 1).

Tabela 1: Média dos resultados encontrados para o parâmetro Staphylococcus coagulase positiva em três marcas de queijo Minas Frescal da região sudeste da Bahia.

\begin{tabular}{c|c|c|c|c|c}
\hline Marca & Média (UFC/g) & Desvio padrão & Máximo (UFC/g) & Mínimo (UFC/g) & Amplitude \\
\hline A & 281.667 & 205466,9 & 630.000 & 90.000 & 540.000 \\
\hline B & 70.167 & 38264,43 & 130.000 & 30.000 & 100.000 \\
\hline C & 130.000 & 86255,43 & 260.000 & 50.000 & 210.000 \\
\hline
\end{tabular}

Os resultados evidenciam uma baixa qualidade microbiológica dos queijos Minas frescal analisados, pois os mesmos apresentaram altos índices de contaminação por micro-organismos, representando um risco à saúde do consumidor.

No Brasil são vários os trabalhos relatando a presença de Staphylococcus em amostras de queijo Minas frescal (PINTO et al., 2011; VALIATTI et al., 2015; SANTANA et al., 2008, PASSOS et al., 2009). As contagens elevadas desse micro-organismo evidenciam eventuais falhas durante e após seu processamento, tais como: pasteurização ineficiente, más condições de higienização dos equipamentos e dos manipuladores, utilização incorreta da temperatura de conservação e condições higiênico-sanitárias insatisfatórias (FORSYTHE, 2013).

Nesse sentido, Mottin e Abreu (2011) salientam que grande parte de manipuladores de alimentos são portadores assintomáticos de Staphylococcus coagulase positiva nas mãos e/ou nas fossas nasais, o que agrava os riscos de contaminação.

Vale ressaltar que, concentrações superiores a $10^{5}$ células/g podem propiciar a produção de enterotoxinas esta- filocócicas, tornando este alimento um risco à saúde do consumidor (FORSYTHE, 2013). No presente estudo, 44,44\% das amostras apresentaram concentrações superiores a $10^{5}$ $\mathrm{UFC} / \mathrm{g}$, sendo que, a marca " $\mathrm{A}$ " apresentou o maior número de amostras nessa condição $(83,33 \%)$ e maior amplitude de resultados. Esses achados servem como indicativo da relação entre a alta contaminação e a falta de padronização dos procedimentos industriais. Nesse contexto, a implantação de Boas Práticas de Fabricação, que visa a diminuição da contaminação dos produtos e a segurança dos alimentos ao consumidor, se torna essencial (FORSYTHE, 2013).

Para a comparação das populações de coliformes totais, cujo grupo de micro-organismos não é destacado na RDC 12 (BRASIL, 2001), utilizou-se a Portaria 146, de 07 de março de 1996, do Ministério da Agricultura, Pecuária e Abastecimento (BRASIL, 1996). Sabe-se que esse grupo de micro-organismos geralmente é contaminante ambiental, e sua contagem elevada indica deficiência na qualidade higiênico-sanitária do produto (BRANT; FONSECA; SILVA, 2007). No presente estudo, $100 \%$ das amostras encontraram-se inadequadas (Tabela 2).

Tabela 2: Média dos resultados encontrados para o parâmetro coliformes totais nas diferentes marcas.

\begin{tabular}{c|c|c|c|c|c}
\hline Marca & Média (UFC/g) & DP & Máximo (UFC/g) & Mínimo (UFC/g) & Amplitude \\
\hline A & 2.367 & 1451,436 & 5.000 & 1.000 & 4.000 \\
\hline B & 112.633 & 155,218 & 315.000 & 1.500 & 313.500 \\
\hline C & 3.383 & 1517,124 & 5.000 & 1.300 & 3.700 \\
\hline
\end{tabular}


Carrijo et al. (2011) e Cereser et al. (2011) encontraram coliformes totais em $100 \%$ das amostras de ricota, considerada, assim como o queijo Minas frescal, produto lácteo de alta umidade. Estes autores afirmam que tais micro-organismos são encontrados na maioria das vezes em leite cru, não sendo observada sua presença após a submissão do leite ao tratamento térmico correto. Desta forma, a contaminação de ricota por coliformes totais pode estar relacionada com a precariedade das condições higiênicas durante sua produção, como também afirmam Kousta et al. (2010), já que o processo de pasteurização objetiva eliminar micro-organismos indicadores e patogênicos.

Neste estudo não foram realizadas análises de coliformes a $45^{\circ} \mathrm{C}$, no entanto, como a $E$. coli é a principal representante deste grupo de micro-organismos, considerou-se que os padrões microbiológicos estabelecidos para coliformes fecais seriam os mesmos para E. coli.

No que tange a este parâmetro, das 18 amostras de queijo Minas Frescal analisadas, 83,33\% estavam acima do limite estabelecido pela legislação vigente, sendo que todas as amostras dentro das normas pertenciam à marca " $A$ " (Tabela 3).

Tabela 3: Média dos resultados encontrados para o parâmetro Escherichia coli nas diferentes marcas.

\begin{tabular}{c|c|c|c|c|c}
\hline Marca & Média (UFC/g) & DP & Máximo (UFC/g) & Mínimo (UFC/g) & Amplitude \\
\hline A & 1.167 & 873,3079 & 2.700 & 500 & 2.200 \\
\hline B & 97.833 & 13,454 & 295.000 & 1.000 & 294.000 \\
\hline C & 1.833 & 983,1921 & 3.000 & 1.000 & 2.000 \\
\hline
\end{tabular}

A literatura relata que a prevalência de amostras de queijo Minas Frescal contaminadas com E. coli é alta. No entanto, os resultados do presente estudo são muito maiores do que os verificados por Feitosa et al. (2003) e Santana et al. (2008), com 36,4\% e 40,0\%, respectivamente.

A contagem de E. coli é utilizada como indicador de contaminação fecal recente ou de condições higiênico-sanitárias insatisfatórias no processamento de alimentos (SILVA; CAVALLI; OLIVEIRA, 2006; JAY, 2005). Além disso, esta bactéria representa um grave problema de saúde pública em todo o mundo em função da gravidade das doenças causadas por meio de sua toxina - diarreia, colite hemorrágica e síndrome hemolítica urêmica (PIGATTO et al., 2009).

A resolução RDC 12 , de 02 de janeiro de 2001 (BRASIL, 2001) permite $5 \times 10^{2} \mathrm{UFC} / \mathrm{g}$ para coliformes termotolerantes, e assim, as médias observadas para as três marcas se mostraram muito acima do permitido. O nível de contaminação para a marca "B" merece maior atenção visto que apresentou contagem de UFC por grama 225 vezes maior que o permitido pela legislação. Assim como o verificado para Staphylococcus, a marca que apresentou maior nível de contaminação também mostrou maior amplitude de resultados.

Nesse sentido, uma reavaliação rigorosa das condições de fabricação, distribuição, comercialização e prazo de validade de queijo Minas Frescal se tornam necessárias para que se possa atender a legislação o mais rápido possível (ROCHA; BURITI; SAAD, 2006).

No presente estudo, verificaram-se correlações moderadas e negativas $(\mathrm{p}<0,01)$ entre as contagens de Staphylococcus com Escherichia coli e coliformes totais (-0,32 e -0,32, respectivamente), e correlação positiva elevada entre Escherichia coli e coliformes totais $(0,99)$.

Uma possível explicação para a correlação negativa entre Staphylococcus e Escherichia coli seria que, em função de os estafilococos serem considerados mal competidores (LOIR; BARON; GAUTIR, 2003), em alimentos com menor microbiota competidora seu desenvolvimento se dá em escala maior. Considerando que a pasteurização do leite visa a total destruição microbiana (CARRIJO et al., 2011; CERESER et al., 2011), que a contaminação por este micro-organismo dar-se-á muitas vezes por meio de manipuladores (MOTTIN;
ABREU, 2011), e que o produto em questão, no seu processo de fabricação, é grandemente manipulado, pode-se justificar a correlação negativa entre os dois patógenos.

Já a correlação positiva entre Escherichia coli e coliformes totais justifica-se, pois os coliformes fecais que inclui três gêneros: Escherichia, Enterobacter e Klebsiella, sendo a cepas de Enterobacter e Klebsiella de origem não fecal e, E. coli, a mais conhecida, sendo do trato gastrintestinal (JAY, 2005; FORSYTHE, 2013; TOROTRA; FUNKE;CASE, 2010) - um sub-grupo dos coliformes, dão uma correlação direta da poluição por fezes de animais de sangue quente. Nesse sentido, Geldreich (1974a) e Geldreich (1974b) salientam que $93,0 \%$ a $98,7 \%$ do total de coliformes totais são de origem fecal.

Corroborando com os achados no presente estudo, a má qualidade microbiológica de queijo Minas Frescal é recorrente em muitos estados brasileiros como, Minas Gerais (APOLINÁRIO; SANTOS; LAVORATO, 2014), Rondônia (VALIATTI et al., 2015), São Paulo (SALOTTI et al., 2006), Bahia (ARAÚJO et al., 2001), Paraná (PINTO et al., 2011), Goiás (RODRIGUES et al., 2011), Rio Grande do Sul (ZOCCHE et al., 2012), Mato Grosso (LOGUERCIO; ALEIXO, 2001) e Rio de Janeiro (BARROS et al., 2004).

A baixa qualidade microbiológica de queijos Minas Frescal no Brasil se deve, muitas vezes, à falta de conhecimento das boas práticas de fabricação por parte dos produtores rurais (VALIATTI et al., 2015).

\section{Conclusão}

Os produtos analisados estavam em desacordo com a legislação, consequentemente, impróprios ao consumo. Assim, entende-se que as condições higiênico-sanitárias para a fabricação do produto não estão adequadas, representando um risco ao consumidor final. Fica evidente a necessidade da implantação de melhorias do controle da produção, por meio de boas práticas de fabricação e da fiscalização efetiva pelos órgãos competentes.

\section{Referências}

APOLINÁRIO, T. C. C.; SANTOS, G. S.; LAVORATO, 
J. A. A. Avaliação da qualidade microbiológica do queijo Minas Frescal produzido por laticínios do estado de Minas Gerais. Revista do Instituto de Laticínios Cândido Tostes, Juiz de Fora, v. 69, n. 6, p. 433-442, 2014.

ARAÚJO, W. N. et al. Isolamento e identificação de coliformes no queijo Minas comercializado na região metropolitana de Salvador - Bahia. Revista Brasileira de Saúde e Produção Animal, Salvador, v. 2, n. 2, p. 37-42, 2001 .

ARRUDA, M. L. T. Ocorrência de Staphylococcus coagulase positiva em queijos minas frescal e padrão de feiras-livres de Goiânia-GO e detecção de genes produtores de enterotoxinas A e B por meio da técnica de duplex PCR. Goiânia, 2006. 82f. Dissertação (Mestrado em Ciência Animal) - Universidade Federal de Goiás.

BARROS, P. C. O. G. et al. Avaliação da qualidade microbiológica do queijo Minas Frescal comercializado no município do Rio de Janeiro, RJ. Revista Higiene Alimentar, São Paulo, v. 18, n. 122, p.57-61, 2004.

BORGES, M. F. et al. Staphylococcus enterotoxigênicos e leites e produtos lácteos, suas enterotoxinas e genes associados: revisão. Boletim do Centro de Pesquisa de Processamento de Alimentos, Curitiba, v. 26, n. 1, p. 7086, 2008

BRANT, L. M. F.; FONSECA, L. M.; SILVA, M. C. C. Avaliação da qualidade microbiológica do queijo-de-minas artesanal do Serro-MG. Arquivo Brasileiro de Medicina Veterinária e Zootecnia, Belo Horizonte, v. 59, n. 6, p. 1570-1574. 2007.

\section{BRASIL. MINISTÉRIO DA AGRICULTURA E DO} ABASTECIMENTO. Secretaria de defesa Agropecuária Portaria ${ }^{\circ} 146$ de 07 de março de 1996. Regulamento Técnico de Identidade e Qualidade de Queijos. Diário Oficial da União, Brasília, DF, mar. 1996.

\section{BRASIL. MINISTÉRIO DA SAÚDE. AGÊNCIA} NACIONAL DE VIGILÂNCIA SANITÁRIA. Resolução RDC n. ${ }^{\circ} 12$, de 02 de janeiro de 2001. Aprova o Regulamento Técnico sobre padrões microbiológicos para alimentos. Diário Oficial da União, Brasília, DF, jan. 2001.

BRASIL. MINISTÉRIO DA AGRICULTURA, PECUÁRIA E ABASTECIMENTO. Secretaria de defesa Agropecuária. Instrução Normativa IN n. ${ }^{\circ}$ 62, de 26 de agosto de 2003. Oficializa os Métodos Analíticos Oficiais para Análises Microbiológicas para Controle de Produtos de origem Animal e Água. Diário Oficial da União, Brasília, DF, ago. 2003 .

CARRIJO, K. F. et al. Avaliação da qualidade microbiológica e físico-química de ricotas frescas comercializadas no município de Niterói, Rio de Janeiro, Brasil. Veterinária Notícias, Uberlândia, v. 17. n. 2, p. 97$110,2011$.
CERESER, N. D. et al. Avaliação da qualidade microbiológica da ricota comercializada em supermercados do estado de São Paulo. Revista de Ciência Animal Brasileira, Goiânia, v. 12, n. 1, p. 149-155, 2011.

FEITOSA, T. et al. Pesquisa de Salmonella sp., Listeria sp. e micro-organismos indicadores higiênico-sanitários em queijos produzidos no estado do Rio Grande do Norte. Ciências e Tecnologia de Alimentos, Campinas, v. 23 (Supl.), p. 162-165, 2003.

FORSYTHE, S. J. Microbiologia da Segurança dos Alimentos. 2.ed. Porto Alegre: Artmed, 2013. 602p.

GELDREICH, E. E. Aspectos microbiológicos dos esgotos e dos seus processos de tratamento. In: Secretaria dos Serviços e Obras Públicas. Desinfecção das águas. São Paulo, CETESB. 1974a, p. 115-34.

GELDREICH, E. E. Qualidade microbiológica em águas potáveis. In: Secretaria dos Serviços e Obras Públicas. Desinfecção das águas. São Paulo, CETESB, 1974b, p. 73-93.

JAY, J. M. Microbiologia de Alimentos. 6 ed. Porto Alegre: Artmed, 2005. 712p.

KOUSTA, M. et al. Prevalence and sources of cheese contamination with pathogens at farm and processing levels. Food control, Amsterdam, v. 21, n. 6, p. 805-815, 2010.

LOGUERCIO, A. P.; ALEIXO, J. A. G. Microbiologia de queijo tipo Minas Frescal produzido artesanalmente. Ciência Rural, Santa Maria, v. 31, n. 6, p. 1063-1067, 2001.

LOIR, Y. L. E., BARON, F., GAUTIR, M. Staphylococcus aureus and food poisoning. Genetic Molecular Research, San Francisco, v. 2, n. 1, p.63-76, 2003.

MOTTIN, V. D.; ABREU, A. F. Pesquisa de Staphylococcus coagulase positiva em manipuladores de produtos cárneos em açougues de Ji-Paraná-Rondônia. Veterinária em Foco, Porto Alegre, v.9, n.1, p.36-42, 2011.

PASSOS, A. L. et al. Avaliação microbiológica de queijos minas frescal comercializados nas cidades de Arapongas e Londrina - PR. Revista do Instituto de Laticínios Cândido Tostes, Juiz de Fora, n. 369, v. 64, p. 48-54, 2009.

PICOLI, S. U. et al. Quantificação de coliformes, Staphylococcus aureus e mesófilos presentes em diferentes etapas da produção de queijo frescal de leite de cabra em laticínios. Ciência e Tecnologia Alimentos, Campinas, v. 26, n. 1, p. 65-69, 2006.

PIGATTO, C. P. et al. Viabilidade de Escherichia coli produtora de toxina shiga (stec) não-O157 em queijo tipo minas frescal. Ciência Animal Brasileira, Goiânia, v. 10, n. 2, p. 663-668, 2009. 
PINTO, F. G. S. et al. Qualidade microbiológica de queijo minas frescal comercializado no município de Santa Helena, PR, BRASIL. Arquivos do Instituto Biológico, São Paulo, v. 78, n. 2, p. 191-198, 2011.

ROCHA, J. S., BURITI, F. C. A, SAAD, S. M. I. Condições de processamento e comercialização de queijo-de-minas frescal. Arquivo Brasileiro de Medicina Veterinária e Zootecnia, Belo Horizonte, v. 58, n. 2, p. 263-272, 2006.

RODRIGUES, J. et al. Levantamento das características físico-químicas e microbiológicas de queijo Minas Frescal e Mussarela produzidos no entorno de Goiânia - GO. Revista da Universidade Vale do Rio Verde, Três Corações, v. 9, Supl. 1, p. 30-34, 2011.

SALOTTI, B. M. et al. Qualidade microbiológica do queijo Minas Frescal comercializado no município de Jaboticabal, SP, Brasil. Arquivos do Instituto de Biologia, São Paulo, v. 73, n. 2, p. 171-175, 2006.

SANTANA, R. F. et al. Qualidade microbiológica de queijocoalho comercializado em Aracaju, SE. Arquivo Brasileiro de Medicina Veterinária e Zootecnia, Belo Horizonte, v. 60, n. 6, p. 1517-1522, 2008.

SILVA, N. da; JUNQUEIRA, V. C. A.; SILVEIRA, N. F. A. Manual de métodos de análise microbiológica de alimentos. 2 ed., São Paulo: Varela, 2001. 317p.

SILVA, M. P.; CAVALLI, D. R.; OLIVEIRA, T. C. R.M. Avaliação do padrão coliformes a $45^{\circ} \mathrm{C}$ e comparação da eficiência das técnicas dos tubos múltiplos e Petrifilm EC na detecção de coliformes totais e Escherichia coli em alimentos. Ciência e Tecnologia de Alimentos, Campinas, v. 26, n. 2, p. 352-359, 2006.

SOUSA, C. P. Segurança alimentar e doenças veiculadas por alimentos: utilização do grupo coliformes como um dos indicadores de qualidade de alimentos. Revista APS, Juiz de Fora, v. 9, n. 1, p. 83-88, 2006.

TORTORA, G. J., FUNKE, B. R., CASE, C. L.

Microbiologia. 10. ed., Porto Alegre: Artmed, 2012. 964p.

VALIATTI, T. B. et al. Avaliação das condições higiênico sanitárias de queijos tipo minas frescal comercializados em feiras no município Ji - Paraná. Revista Científica da Faculdade de Educação e Meio Ambiente, Ariquemes, v. 6, n. 1, p. 59-68, 2015

VIEIRA, K. P. et al. Contaminação de queijo Minas Frescal por bactérias patogênicas: Um risco á saúde. ConScientia e Saúde, São Paulo, v. 7, n. 2, p. 201- 206, 2008.

ZOCCHE, F. et al. Estafilococos coagulase positiva em queijos Minas Frescal e Minas Padrão comercializados em Pelotas, Rio Grande do Sul. Boletim Centro de Pesquisa de Processamento de Alimentos, Curitiba, v. 30, n. 1, p. 119-124, 2012.
Recebido em: 06.05.2016

Aceito em: 01.12.2016 